\title{
MMP-1 is overexpressed in triple-negative breast cancer tissues and the knockdown of MMP-1 expression inhibits tumor cell malignant behaviors in vitro
}

\author{
QI-MIN WANG, LI LV, YING TANG, LI ZHANG and LI-FEN WANG \\ Department of Pathology, The Second Hospital, Dalian Medical University, Dalian, Liaoning 116027, P.R. China
}

Received October 25, 2017; Accepted October 19, 2018

DOI: $10.3892 / \mathrm{ol} .2018 .9779$

\begin{abstract}
Matrix metalloproteinase 1 (MMP-1) is a member of the zinc-dependent endopeptidase family, which cleaves the extracellular matrix. The present study investigated the functional role of MMP-1 in breast cancer ex vivo and in vitro in order to determine the underlying molecular mechanisms. The levels of MMP-1 were analyzed in 99 breast cancer specimens using immunohistochemistry and western blotting. A stable short hairpin RNA (shRNA) knockdown of MMP-1 expression was performed in MCF-7 and MDA-MB-231 breast cancer cells, and the effects were examined using MTT and colony formation assays, as well as migration and invasion assays, while western blotting was used to detect the activation of intracellular signaling. The MMP-1 protein was more highly expressed in triple-negative breast cancer tissues than in estrogen receptor(+) and human epidermal growth factor 2 receptor(3+) breast cancer tissues $(\mathrm{P}<0.05)$. Furthermore, the MMP-1 levels were significantly higher in the tumor and tumor stromal cells of lymph node metastatic breast cancer tissues than in those of non-metastatic tissues. The knockdown of MMP-1 expression in MCF-7 and MDA-MB-231 cells using MMP-1 shRNA significantly inhibited cell proliferation, migration and invasion, and the expression of the Myc proto-oncogene protein, phosphorylated and total RAC- $\alpha$ serine/threonine-protein kinase 1, and B-cell lymphoma 2, but increased the protein levels of apoptosis regulator BAX and caspase 3 . In conclusion, the data suggest that MMP-1 serves an important role in breast cancer development and metastasis. Future studies should assess MMP-1 as a prognostic marker for patients with breast cancer and its inhibition as a novel strategy for controlling breast cancer.
\end{abstract}

Correspondence to: Dr Li-Fen Wang, Department of Pathology, The Second Hospital, Dalian Medical University, 467 Zhongshan Road, Dalian, Liaoning 116027, P.R. China

E-mail: lifen_w@163.com

Key words: breast cancer, matrix metalloproteinase 1, short hairpin RNA, prognosis

\section{Introduction}

Breast cancer is a significant health burden for women worldwide despite decades-long advancement in early detection, prevention, treatment strategies and pathogenesis studies (1-3). However, a subset of breast cancer types positive for estrogen receptor (ER), progesterone receptor (PR) and human epidermal growth factor 2 receptor (HER2) proteins have been effectively controlled by hormone or molecular targeted therapies (4,5). By contrast, triple-negative breast cancer (TNBC), with no ER, PR or HER2 expression, is a biologically aggressive neoplasm with a poor prognosis, frequent relapses and visceral metastasis due to a lack of effective treatment options $(6,7)$. Therefore, further investigations into the underlying molecular mechanisms responsible for TNBC progression and metastasis could aid medical oncologists in effectively controlling this deadly disease.

Matrix metalloproteinases (MMPs) are a family of zinc-dependent proteases that degrade the extracellular matrix during physiological processes, including embryonic development, human reproduction, tissue remodeling and disease states $(8,9)$. It has been revealed that, during cancer development and progression, MMPs are upregulated in tumor and stromal cells compared with normal, benign or premalignant tissues (10). Proteolysis of the extracellular matrix by MMPs leads to tumor cell invasion and metastasis of breast cancer $(11,12)$. To date, >25 MMPs have been identified as collagenases, gelatinases, stromelysins, matrilysins and membrane-type MMPs (13). MMP-1, an interstitial collagenase, is one of the most widely expressed MMPs and is able to degrade type I, II and III collagens. Elevated MMP-1 expression has been reported in bladder cancer and was revealed to be associated with a poor prognosis in these patients (14), as well as in patients with prostate cancer (15) and gastric cancer (16). The MMP-1 level is also markedly upregulated in breast cancer and stromal cells, and is associated with breast cancer progression and poor prognosis (17).

Therefore, in the present study, MMP-1 levels in normal and invasive breast cancer tissue samples were first detected in order to analyze the association with clinicopathological data from patients. The MMP-1 expression was then knocked down in breast cancer MCF-7 and MDA-MB-231 cell lines using MMP-1 siRNA, and the effect of MMP-1-knockdown on tumor cell proliferation, migration and invasion was determined. The 
aim of the study was to be able to provide useful information regarding MMP-1 as a potential biomarker in breast cancer progression and to target MMP-1 for breast cancer treatment.

\section{Materials and methods}

Tissue samples. In the present study, tissue specimens were collected from 99 female patients with breast cancer, who underwent surgical resection of tumor lesions and medical care in The Second Hospital, Dalian Medical University (Dalian, China) between January and December of 2017. No patients received any preoperative radiotherapy, endocrine therapy or chemotherapy, and all were histologically diagnosed with invasive breast cancer and staged according to the World Health Organization classification (18). Tissues were fixed in $10 \%$ formalin and embedded in paraffin and the tissue blocks (4 $\mu \mathrm{M}$-thick sections) were retrieved from the Department of Pathology for preparation of normal and cancerous tissue specimens for immunohistochemistry. The fresh breast cancer specimens were collected, snapped-frozen in liquid nitrogen and stored at $-80^{\circ} \mathrm{C}$ for $<6$ months until use.

The research protocol of the present study was approved by the Ethics Committee of the Second Hospital of Dalian Medical University (certification no. 2017-39), and written informed consent was obtained from all patients prior to enrollment.

Immunohistochemistry. Immunohistochemical analysis of protein expression was performed on formalin-fixed and paraffin-embedded tissue sections (4 $\mu \mathrm{M}$ thickness) using the EnVision kit (Fuzhou Maixin Biotech Co., Ltd., Fuzhou, China) according to the manufacturer's protocols. The MMP-1 antibody (cat. no. ab52631; Abcam, Cambridge, UK) and antibodies against ER (cat. no. 6F11), PR (cat. no. EP2), HER2 (cat. no. EP3) and cytokeratin (CK)5/6 (cat. no. CK5/6.007) which were obtained from ZSGB Biotech Co., Ltd (Beijing, China) were used at a dilution of 1:100 following the manufacturer's protocols. The immunostained tissue sections were reviewed and assessed under a light microscope (magnification, $\mathrm{x} 200$ and $\mathrm{x} 400$ ) by two independent researchers in a blinded manner from the Department of Pathology (The Second Hospital, Dalian Medical University, Dalian China); discrepancies were resolved by discussion until a consensus was reached. Positive expression of the ER and PR proteins was defined by $10 \%$ stained nuclei, while positive expression for MMP-1 and CK5/6 was defined as $10 \%$ stained cytoplasm as the cut-off values for positive immunostaining. The TNBC specimens (ER-, PRand HER2-) were further stained with basal CK5/6. A score of $3+$ for HER2 immunostaining was defined as strong and complete membrane positivity for staining in $>10 \%$ invasive tumor cells (19).

Cell lines and culture. Human breast cancer MCF-7 and MDA-MB-231 cell lines were acquired from the Shanghai Cell Bank of Chinese Academy of Sciences (Shanghai, China) and grown in Dulbecco's modified Eagle's medium with high glucose containing $10 \%$ fetal bovine serum (both Gibco; Thermo Fisher Scientific, Inc., Waltham, MA, USA), penicillin $(100 \mathrm{U} / \mathrm{ml})$, and streptomycin $(100 \mathrm{mg} / \mathrm{ml})$ at $37^{\circ} \mathrm{C}$ in a humidified incubator with $5 \%$ carbon dioxide.
Construction of MMP-1 short hairpin RNA (shRNA) vector and transfection into tumor cells. An MMP-1 shRNA was utilized to knock down the expression of MMP-1 in MCF-7 and MDA-MB-231 cells. Specifically, MMP-1 shRNA and control (mock) DNA sequences were cloned into multiple cloning sites of a GV102 vector (Shanghai Genechem Co., Ltd., Shanghai, China) to generate GV102-MMP1-shRNA (shRNA-MMP1\#1, shRNA-MMP1\#2 and shRNA-MMP1\#3) and a GV102-control (shRNA-mock). The target sequences against MMP-1 were 5'-CACATGACTTTCCTGGAAT-3', 5'-CTAGAACTGTGAAGCATAT-3' and 5'-ACAATTTCA GAGAGTACAA-3', respectively, and the negative control sequence was 5'-TTCTCCGAACGTGTCACGT-3'. Following DNA sequencing confirmation, the vectors were transfected into the breast cancer cells.

Breast cancer MCF-7 and MDA-MB-231 cells were plated into a 6 -well plate, grown to reach $80 \%$ confluence and then transfected with these plasmids ( $2 \mu \mathrm{g}$ each well) (shRNA-MMP1\#1, shRNA-MMP1\#2, shRNA-MMP1\#3 or shRNA-mock) using Lipofectamine ${ }^{\mathrm{TM}} 2000$ (Invitrogen; Thermo Fisher Scientific, Inc.) for $48 \mathrm{~h}$, according to the manufacturer's protocol.

Western blot analysis. A western blot assay was used to assess the levels of MMP-1, the Myc proto-oncogene protein (c-Myc), phosphorylated and total RAC- $\alpha$ serine/threonine-protein kinase (AKT), B-cell lymphoma 2 (Bcl-2), apoptosis regulator BAX (BAX) and caspase 3 in the shRNA-transfected cells, and MMP-1 expression in 14 ER(+), 7 HER2(3+) and 7 TNBC tissue samples. In brief, total cellular protein was extracted from the breast cancer tissues or cells using radioimmunoprecipitation assay buffer (Beijing Solarbio Science \& Technology Co., Ltd., Beijing, China), and the protein concentration was determined using a bicinchoninic acid assay. The protein samples (25 $\mu \mathrm{g}$ each) were separated in a 10\% SDS-PAGE gel and transferred onto a nitrocellulose membrane. The membrane was then incubated in 5\% skimmed milk with Tween-20 TBST suspension buffer for $4 \mathrm{~h}$ at room temperature, then with the specified primary antibodies at $4^{\circ} \mathrm{C}$ overnight, and finally with the secondary antibodies conjugated with horseradish peroxidase for $2 \mathrm{~h}$ at room temperature. Positive protein bands were visualized with an enhanced chemiluminescence reagent (Gene Tech Biotechnology Co., Ltd., Shanghai, China). The ImageJ1.42q software (National Institutes of Health, Bethesda, MD, USA) was used to quantify the protein expression levels. The commercial antibodies used in this assay were MMP-1 (dilution, 1:500; cat. no. ab52631), c-Myc (dilution, 1:1,000; cat. no. ab39688; both Abcam), p-AKT (dilution, 1:1,000; cat. no. 9275), AKT (dilution, 1:1,000; cat. no. 9272; both Cell Signaling Technology, Inc., Danvers, MA, USA), Bcl-2 (dilution, 1:1,000; cat. no. bs-20351R), BAX (dilution, 1:1,000; cat. no. bs-4564R) and caspase 3 (dilution, 1:1,000; cat. no. bsm-33199M) and GAPDH (dilution, 1:5,000; cat. no. bs-0755R; all BIOSS, Beijing, China). The rabbit-derived primary antibody was followed by incubation with goat anti-rabbit secondary antibody (dilution, 1:5,000; cat. no. ZB2301; OriGene Co. Ltd, Beijing, China) and the mouse-derived primary antibody with goat anti-mouse secondary antibody (dilution, 1:5,000; cat. no. A0216; Beyotime Co. Ltd, Shanghai, China). 
Cell proliferation and colony formation assays. Cell proliferation was determined with an MTT assay. Following the transfection with the shRNA plasmids, the MCF-7 and MDA-MB-231 cells were seeded at $2 \times 10^{3}$ cells/well into 96-well plates, and grown for up to $72 \mathrm{~h}$ at $37^{\circ} \mathrm{C}$ with $5 \% \mathrm{CO}_{2}$. At the end of each experiment, $20 \mu \mathrm{l}$ MTT solution $(5 \mathrm{mg} / \mathrm{ml})$ was added to the cells, and they were further incubated at $37^{\circ} \mathrm{C}$ for $4 \mathrm{~h}$. Subsequently, the cell culture medium was replaced with $100 \mu 1$ dimethyl sulfoxide and the optical density was assessed at $490 \mathrm{~nm}$ using a spectrophotometer (Beijing Liuyi Biotechnology Co., Ltd., Beijing, China).

For the colony formation assay, 250 cells per well were seeded into 6 -well plates and incubated for 11 days at $37^{\circ} \mathrm{C}$ with $5 \% \mathrm{CO}_{2}$ until visible colonies appeared. The cell culture medium was poured out and the cells were washed with PBS three times, followed by staining with $0.5 \%$ Giemsa. Cell colonies with $\geq 50$ cells were counted under a microscope (Olympus Corp., Tokyo, Japan). These assays were performed in triplicate and repeated $\geq 3$ times.

Tumor cell wound-healing assay. Following the 48-h shRNA-control or shRNA-MMP-1 transfection, the MDA-MB-231 and MCF-7 cells were detached and re-seeded into a 6 -well plate at a density of $1 \times 10^{5}$ cells per well. The cells were grown to $\sim 95 \%$ confluence and scratch wounds were made in the cell monolayer using a $200-\mu 1$ pipette tip. Following washing with ice-cold PBS, the cells were then continuously cultured for 24 and $48 \mathrm{~h}$ at $37^{\circ} \mathrm{C}$ with $5 \% \mathrm{CO}_{2}$ during which time images were captured under an inverted microscope (Olympus Corp.).

Tumor cell migration and invasion assays. Transwell 24-well inserts with 8-mm pore size filters (Corning Life Sciences, Corning, NY, USA) were used to assess the tumor cell migration and invasion capacity. For tumor cell invasion ability, the membranes were pre-coated with $20 \mu$ l Matrigel (dilution, 1:3; BD Biosciences, Franklin Lakes, NJ, USA). Following the 48-h shRNA-control or shRNA-MMP-1 transfection, $2.5 \times 10^{4}$ cells in $0.2 \mathrm{ml}$ growth DMEM were seeded into the upper chambers, with $0.5 \mathrm{ml}$ growth medium containing $20 \% \mathrm{FBS}$ in the lower chambers. The cells were incubated for $24 \mathrm{~h}$ at $37^{\circ} \mathrm{C}$, and any cells that had invaded or migrated (separate experiment using a membrane without the Matrigel pre-coating) to the reverse side of the membrane were detected by staining with $0.1 \%$ crystal violet for $30 \mathrm{~min}$ at room temperature, and viewed and counted under a light microscope at magnification, x200.

Statistical analysis. All statistical analyses were performed with the SPSS v16.0 software (SPSS Inc., Chicago, IL, USA). Data are presented as the mean \pm standard deviation. Categorical data were analyzed using the $\chi^{2}$ test, while quantitative data were compared with a two-tailed Student's t-test between groups and a one-way analysis of variance among multiple groups followed by Lease Significant Difference post hoc test. $\mathrm{P}<0.05$ was considered to indicate a statistically significant difference.

\section{Results}

Patient characteristics. In the cohort of 99 patients, with a mean age of 54 years at surgery (range, 32-86 years), all were histologically diagnosed with invasive breast cancer. Histologically, 28 ER(+), 22 HER2(3+) and 26 TNBC cases were observed. The remaining 23 samples could not be categorized in the aforementioned groups as they were HER2(2+) and/or indicated to express ER in the cytoplasm of tumor cells. Tissue specimens were obtained during surgery and subjected to formalin fixation and paraffin-embedding, while fresh tissue samples from a number of patients were also collected for western blotting. The basic clinicopathological data of the patients and their association with the MMP-1 histology results are listed in Table I.

High MMP-1 expression in breast cancer tissues. In the present study, MMP-1 expression was first detected in breast cancer tissues using immunohistochemistry, and it was revealed that the MMP-1 protein was expressed in $62.63 \%$ (62/99) of breast cancer tissues and in $71.72 \%$ (71/99) of tumor stroma samples (Fig. 1). MMP-1 expression was significantly higher in cases with lymph node metastasis than in non-lymph node metastasis cases in breast cancer tissues and the tumor stroma $(\mathrm{P}<0.05)$, but was not associated with the age of the patient, menopausal status, tumor size, histological grade or clinical stage $(\mathrm{P}>0.05)$ (Table I).

The immunohistochemical and western blotting data revealed that the highest levels of MMP-1 expression were in the TNBC tissues, and that they were significantly higher than those measured in ER(+) and HER2(3+) breast cancer tissues $(\mathrm{P}<0.05$; Table I). Additionally, immunohistochemistry revealed that MMP-1 expression was highest in the tumor stroma of TNBC tissues $(\mathrm{P}<0.05$; Table I).

Knockdown of MMP-1 expression inhibits tumor cell malignant behaviors. The effects of MMP-1-knockdown on breast cancer cell proliferation and colony formation ability were assessed, and the level of MMP-1 protein was significantly lower in the shRNA-MMP1\#2-transfected tumor cells than that in the shRNA control cells (Fig. 2A), indicating that MMP-1 shRNA was able to knockdown MMP-1 expression in breast cancer cells. The changes in tumor cell phenotypes were assessed and it was revealed that, compared with the shRNA-control-transfected cells, the shRNA-MMP-1-transfected cells exhibited significantly decreased proliferation (Fig. 2B). Additionally, compared with the shRNA-MMP-1-transfected cells, the colony numbers of the shRNA-control MCF-7 and MDA-MB-231 cells were significantly higher (Fig. 2C).

The Transwell invasion assay revealed a significant reduction in the invasion of the shRNA-MMP-1-transfected cells compared with that of the shRNA-control-transfected cells (Fig. 3A). In addition, the tumor cell wound-healing assay demonstrated that the motile ability of the shRNA-MMP-1-transfected cells was poorer than that of the shRNA-control cells (Fig. 3B).

Knockdown of MMP-1 expression alters the expression of $c-M y c, p-A K T, A K T, B c l-2, B A X$ and caspase 3. A previous study has demonstrated that MMP-1 is able to alter the expression of cell growth/apoptosis- and mobility-associated proteins (20). In agreement with these findings, the results of the western blot analysis in the present study revealed that shRNA-MMP-1 
Table I. Expression of MMP-1 and its association with clinicopathological parameters in breast cancer tissues.

Positivity of MMP-1 expression

\begin{tabular}{|c|c|c|c|c|c|c|c|}
\hline \multirow[b]{3}{*}{ Parameter } & \multirow[b]{3}{*}{ Total patients, $\mathrm{n}$} & \multirow{2}{*}{\multicolumn{3}{|c|}{ Breast cancer tissue }} & \multirow{2}{*}{\multicolumn{3}{|c|}{$\overline{\text { Breast cancer-associated stroma }}$}} \\
\hline & & & & & & & \\
\hline & & $\mathrm{n}$ & Rate, $\%$ & P-value & $\mathrm{n}$ & Rate, $\%$ & P-value \\
\hline Age, years & & & & 0.728 & & & 1.000 \\
\hline$\leq 50$ & 41 & 27 & 65.85 & & 29 & 70.73 & \\
\hline$>50$ & 58 & 35 & 60.34 & & 42 & 72.41 & \\
\hline Menopause & & & & 0.416 & & & 0.980 \\
\hline Yes & 55 & 32 & 58.18 & & 40 & 72.73 & \\
\hline No & 44 & 30 & 68.18 & & 31 & 70.45 & \\
\hline Axillary nodal status & & & & $0.027^{\mathrm{a}}$ & & & $0.019^{\mathrm{a}}$ \\
\hline$\geq \mathrm{N} 1$ & 45 & 34 & 75.56 & & 38 & 84.44 & \\
\hline No & 54 & 28 & 51.85 & & 33 & 61.11 & \\
\hline Tumor size, $\mathrm{cm}$ & & & & 0.773 & & & 0.826 \\
\hline$\leq 2$ & 53 & 32 & 60.38 & & 39 & 73.58 & \\
\hline$>2$ & 46 & 30 & 65.22 & & 32 & 69.57 & \\
\hline Grade & & & & 0.067 & & & 0.059 \\
\hline I & 6 & 2 & 33.33 & & 2 & 33.33 & \\
\hline II & 56 & 38 & 67.86 & & 39 & 69.64 & \\
\hline III & 37 & 22 & 59.46 & & 30 & 81.08 & \\
\hline Stage & & & & 0.128 & & & 0.404 \\
\hline $\mathrm{I} / \mathrm{II}$ & 70 & 40 & 57.14 & & 48 & 68.57 & \\
\hline III/IV & 29 & 22 & 75.86 & & 23 & 79.31 & \\
\hline IHC status & & & & $0.017^{\mathrm{a}}$ & & & $0.018^{\mathrm{a}}$ \\
\hline $\mathrm{ER}(+)$ & 28 & 11 & 39.29 & & 17 & 60.71 & \\
\hline HER2(3+) & 22 & 14 & 63.64 & & 16 & 72.73 & \\
\hline TNBC & 26 & 20 & 76.92 & & 24 & 92.31 & \\
\hline
\end{tabular}

${ }^{\text {aP }}<0.05$. MMP-1, matrix metalloproteinase 1; IHC, immunohistochemistry; ER, estrogen receptor; HER2, human epidermal growth factor 2 receptor; TNBC, triple-negative breast cancer. The remaining 23 samples could not be categorized as they were HER2(2+) and/or indicated to express ER in the cytoplasm of tumor cells.

transfection in MCF-7 and MDA-MB-231 cells led to a marked decrease in the protein levels of c-Myc, p-AKT, AKT, and Bcl-2, and an increase in the levels of BAX and caspase 3 compared with those of the shRNA-control cells (Fig. 4).

\section{Discussion}

MMPs serve an important role in tissue remodeling and disease progressions; accordingly, their overexpression in a number of types of cancer has been reported in various human cancer types, including lung and breast cancers $(21,22)$. The degradation of the basement membrane by MMPs is considered to be crucial in breast cancer cell invasion and metastasis $(23,24)$, and the downregulation or reduced expression of MMP proteins has been demonstrated to inhibit cancer development and metastasis (20). MMP-1 has been revealed to be upregulated in breast cancer (25); confirmation of this and a better understanding of MMP-1 overexpression in breast cancer may provide a novel insight into the role of MMP-1 in breast cancer pathogenesis and progression.
Based on DNA microarray profiling, breast cancer is currently divided into five phenotypes: Luminal A, luminal B, HER2, normal breast-like and basal-like breast cancer (26-28), each of which is managed with different treatment regimens and conveys a different prognosis. For example, the majority of basal-like breast cancer subtypes are classified as TNBC following negative immunohistochemical staining for ER, PR, and HER 2 proteins. These molecular classifications reflect gene expression and are important for cancer treatment using hormone therapy or HER2-targeted therapy. To date, treatment strategies have been established for the luminal and HER2-positive breast cancers; however, an effective treatment for the basal-like breast cancer type remains undiscovered. Therefore, novel therapeutic strategies for TNBC treatment are required in order to prolong the survival of patients. The present study focused on MMP-1 for biomarker discovery and as a target for breast cancer therapy using MMP-1 shRNA. MMP-1 protein was revealed to be highly expressed in $>60$ specimens of breast cancer tissue and $>70$ of tumor stroma. MMP-1 expression was revealed to be associated with breast cancer 

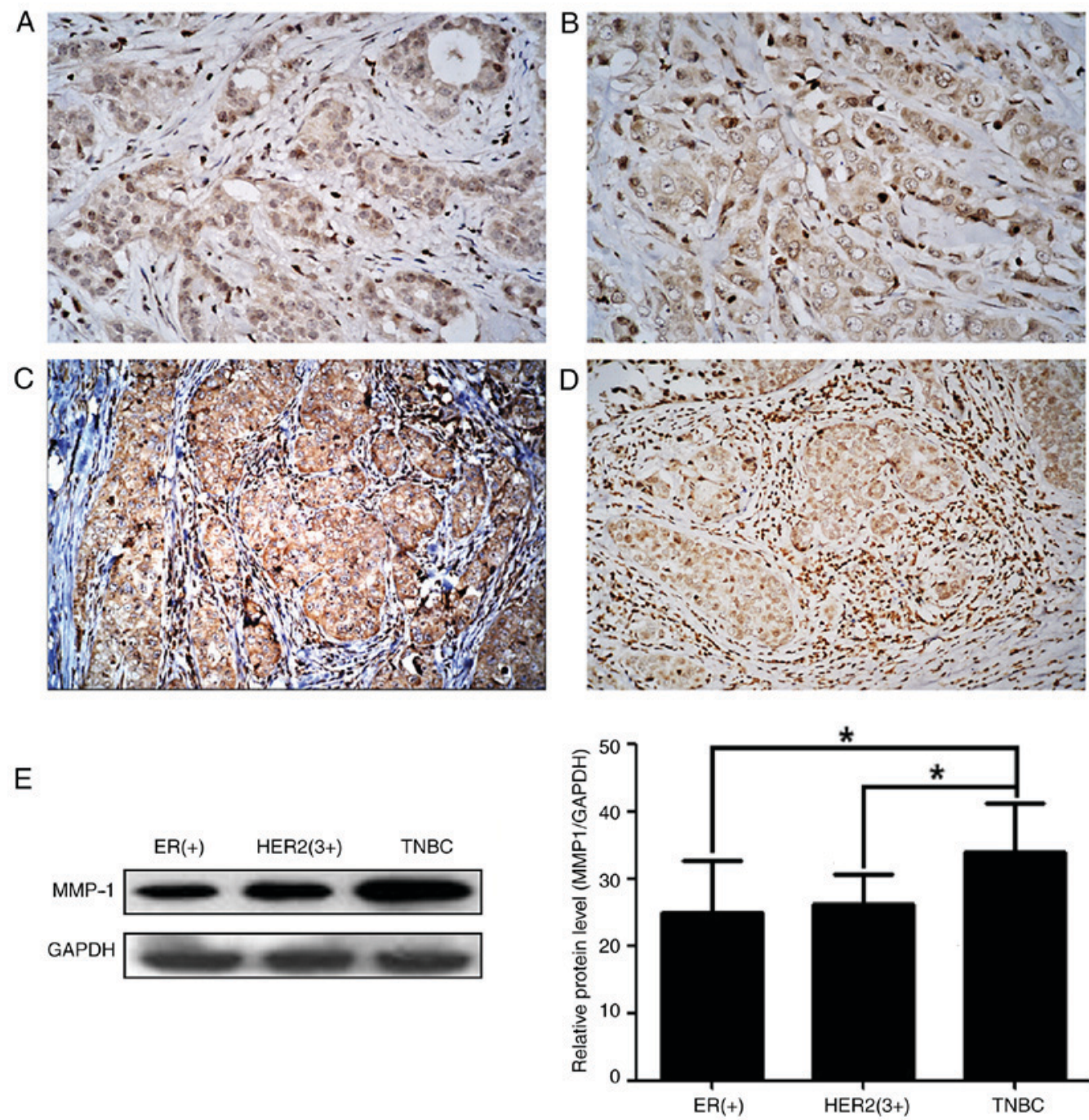

Figure 1. High expression of MMP-1 protein in breast cancer and tumor stroma tissues. MMP-1 expression was assessed in breast cancer tissues of (A) ER(+) samples, (B) HER2(3+) samples and (C) TNBC samples using immunohistochemistry. (D) Immunohistochemistry image of strong MMP-1 expression in breast cancer-associated stromal cells. Original magnification, x200. (E) Western blotting results. The levels of MMP-1 protein were significantly higher in the TNBC tissues than in the ER(+) and HER2(3+) breast cancer tissues. GAPDH was used to normalize the protein expression levels. ${ }^{*}<0.05$ using analysis of variance. The data represent three independent experiments. MMP-1, matrix metalloproteinase 1; ER, estrogen receptor; HER2, human epidermal growth factor 2 receptor; TNBC, triple-negative breast cancer.

lymph node metastasis and TNBC, but was independent of the age of the patient, menopausal status, tumor size, histological grade and clinical stage. The in vitro experiments of the present study demonstrated that MMP-1-knockdown inhibited tumor cell malignant behaviors, including tumor cell proliferation, migration and invasion. Furthermore, MMP-1-knockdown suppressed the protein expression of c-Myc, p-AKT, AKT and $\mathrm{Bcl}-2$, but induced the expression of BAX and caspase 3 , in breast cancer cells. The results demonstrated the importance of MMP-1 in breast cancer development and progression. Further studies may confirm MMP-1 as a biomarker for breast cancer progression or as a target for the clinical management of breast cancer.

Notably, certain studies have demonstrated that the upregulation of MMP-1 expression occurs in grade III breast cancer $(29,30)$. Other studies have further revealed MMP-1 expression to be associated with a poor clinical outcome, including breast cancer metastasis and a poor prognosis (17,31-34). The results of the present study revealed that MMP-1 protein was highly expressed in invasive breast cancer cells and stroma, and that its expression was associated with breast cancer metastasis to the lymph nodes and the TNBC subtype, which was in accordance with previous studies (17,31-36). However, these findings are not consistent with a study by Przybylowska et al (37), in which MMP-1 expression was demonstrated to be associated with lymph node-negative breast cancer. The reason for this discrepancy is unknown and requires further investigation with a larger sample population from multiple centers.

Furthermore, a previous study demonstrated that the stromal expression of MMP-1 protein was significantly associated with the luminal A, luminal B, HER2-positive and TNBC subtypes (17). Significant MMP-1 overexpression in tumor and stromal cells in ER(+), HER2(3+) and TNBC was similarly revealed in the present study, suggesting that MMP-1 overexpression in breast cancer and tumor stromal cells is associated with metastasis in invasive breast cancer and TNBC. The molecular profile of the lethal breast cancer 
A

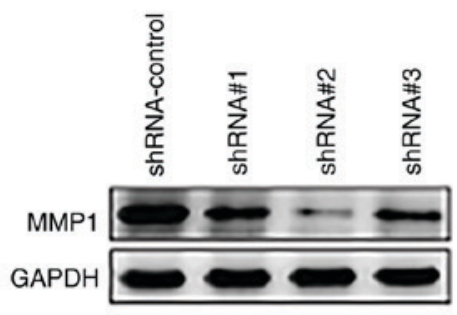

B

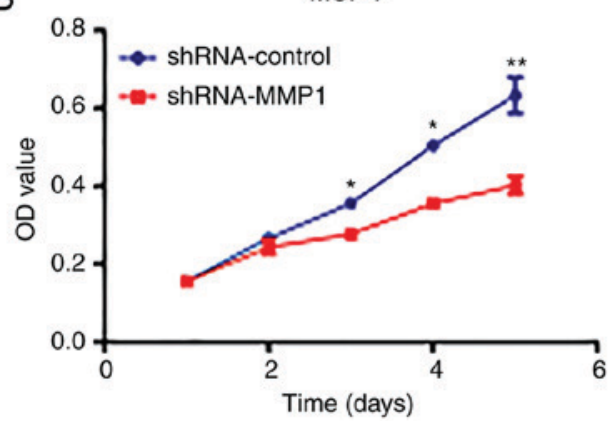

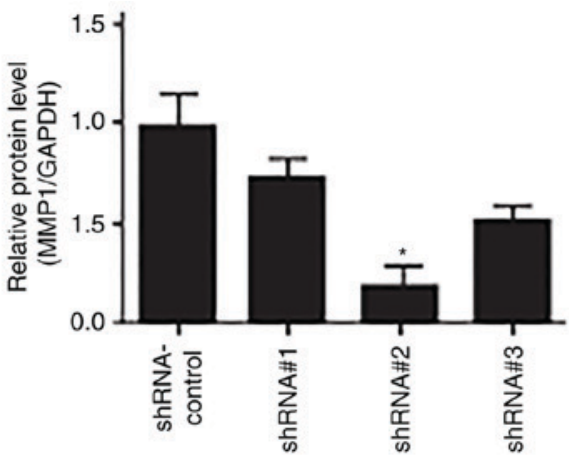

MDA-MB-231

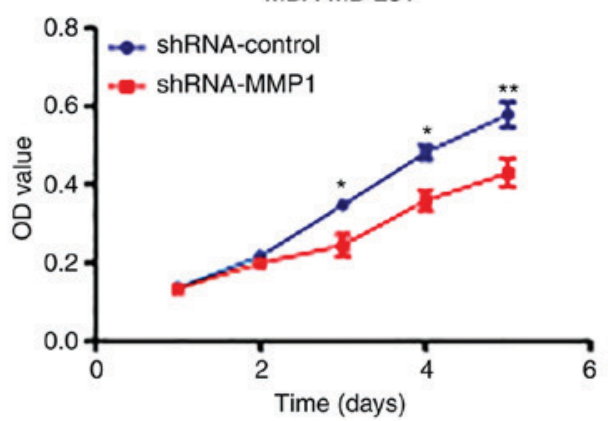

C

ShRNA-control
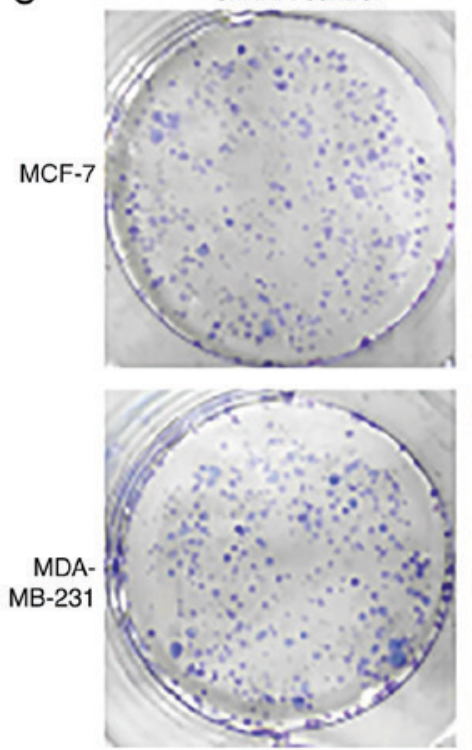

ShRNA-MMP1
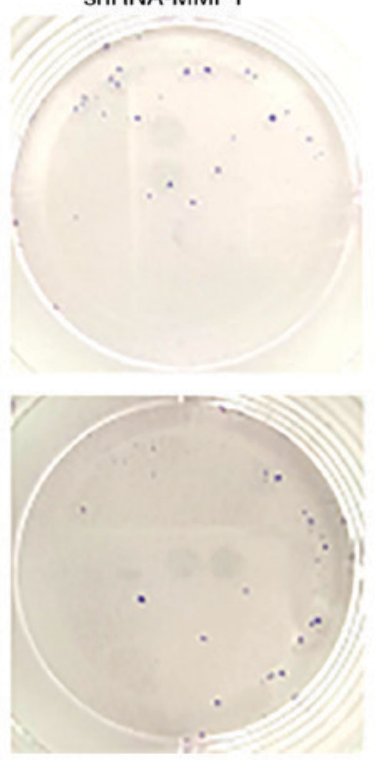
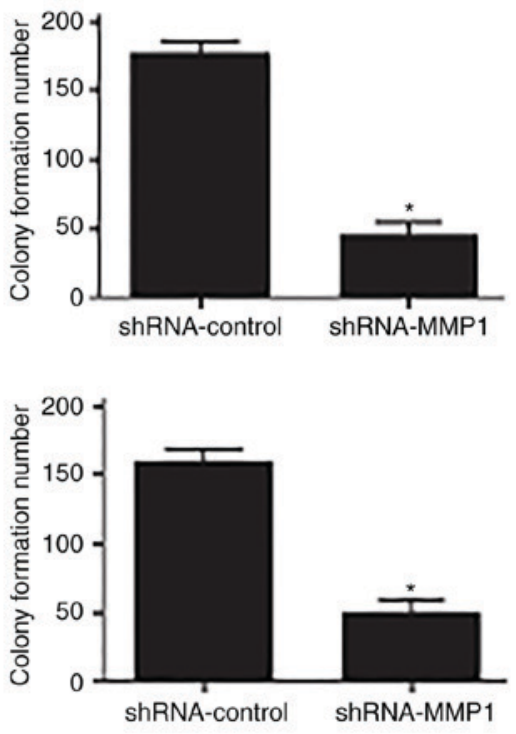

Figure 2. Inhibition of breast cancer cell proliferation following MMP-1-knockdown. (A) Western blot analysis. The level of MMP-1 protein was knocked down in MCF-7 cells using shRNA-MMP-1. ${ }^{*} \mathrm{P}<0.05$ using analysis of variance. (B) MTT assay. MMP-1-knockdown significantly reduced tumor cell proliferation in the MCF-7 and MDA-MB-231 cells. ${ }^{*} \mathrm{P}<0.05$ and ${ }^{* *} \mathrm{P}<0.01$ using an unpaired Student's t-test. (C) Colony formation assay. The number of colonies formed was significantly reduced in breast cancer cells expressing shRNA-MMP-1 compared with that in the shRNA-control cells. * $<<0.05$ using an unpaired Student's $\mathrm{t}$-test. The data presented are the mean \pm standard deviation from three independent experiments. MMP-1, matrix metalloproteinase 1; shRNA, short hairpin RNA; OD, optical density.

microenvironment is based on activated cancer-associated fibroblasts (38). MMP-1 is able to promote cancer metastasis through degradation of the extracellular matrix, angiogenesis, osteoclast activation and tumor cell invasion $(39,40)$, facilitating angiogenesis and increasing extracellular matrix degradation, which are important processes for the invasive and migratory phenotype of metastatic breast cancer. Breast cancer metastasis is closely associated with the changes in the surrounding carcinomatous interstitium, and aberrant MMP-1 expression affects this, making it a potential biomarker to assess TNBC metastasis and prognosis. The present study demonstrated that knocking down MMP-1 expression not only suppressed cancer cell proliferation, but also inhibited the tumor cell migration and invasion capacity, which was in agreement with previous studies using shRNA technology in MDA-MB-231 breast cancer cells (41-43).

In addition, the oncogenic c-Myc protein serves a potent role in the development and progression of a variety of human cancer types (44). Previous studies have demonstrated that c-Myc is highly expressed in basal-like breast cancer (45-47) and that its 
A

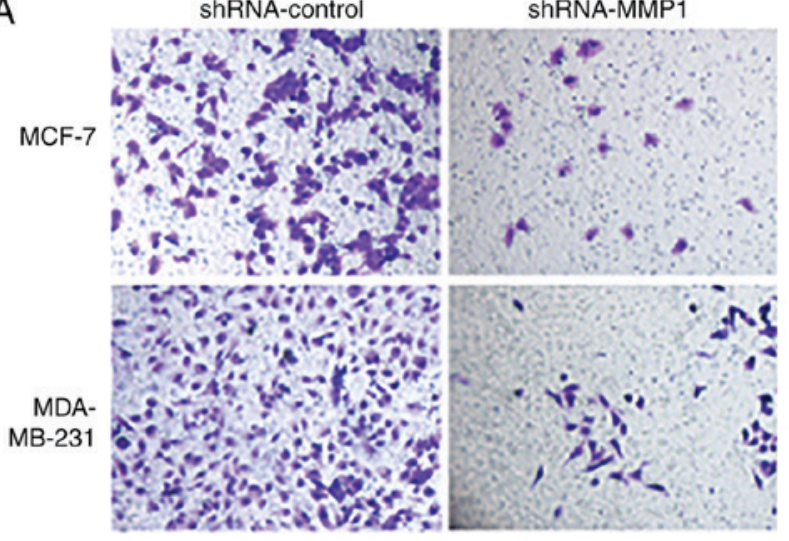

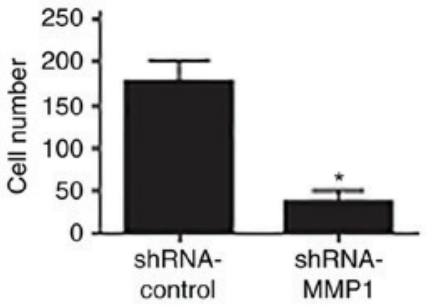

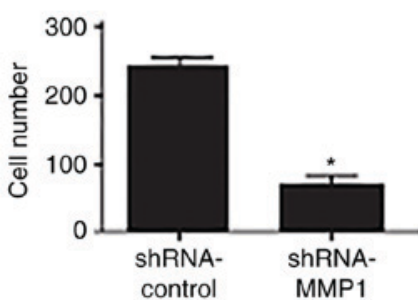

B
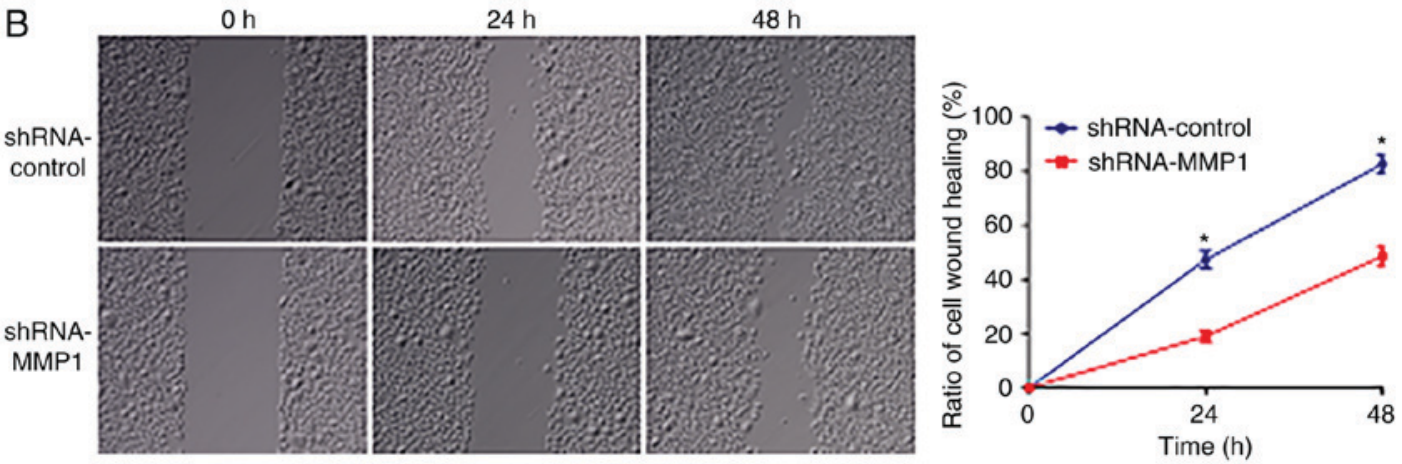

Figure 3. Inhibition of the migration and invasion of breast cancer cells following the MMP-1-knockdown. (A) Transwell invasion assay. MCF-7 and MDA-MB-231 cells transfected with shRNA-MMP-1 or shRNA-control were applied to the upper chamber of Transwell inserts. After $24 \mathrm{~h}$, the cells that invaded into the inverse surface of membrane were stained with $0.1 \%$ crystal violet and counted. Magnification, x100. (B) Wound healing assay. The motile ability of shRNA-MMP-1 and shRNA-control MCF-7 cells was assessed. " $\mathrm{P}<0.05$, determined by Student's t-test. The data presented are the mean \pm standard deviation from three independent experiments. Magnification, x100. MMP-1, matrix metalloproteinase 1; shRNA, short hairpin RNA.
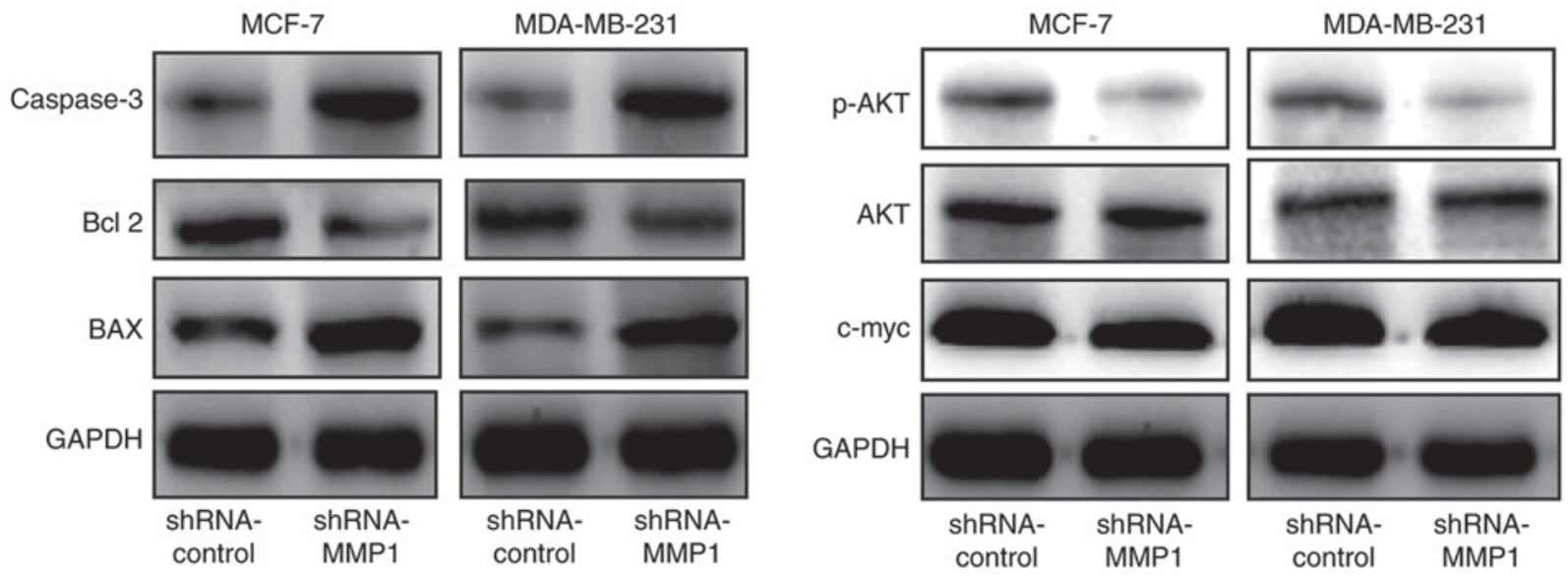

Figure 4. Inhibition of gene expression in breast cancer cells after the knockdown of MMP-1 expression. Western blotting was performed to assay the expression of c-Myc, p-AKT, AKT, Bcl-2, BAX, and caspase 3 in the shRNA-MMP-1 transfected MCF-7 and MDA-MB-231 cells compared to that in the control shRNA-control cells. The data revealed a marked reduction in expression of c-Myc, p-AKT, AKT, Bcl-2, but increase in expression of BAX and caspase 3 in the shRNA-MMP-1 transfected MCF-7 and MDA-MB-231 cells compared the control shRNA-control cells. MMP-1, matrix metalloproteinase 1; shRNA, short hairpin RNA; Bcl-2, B-cell lymphoma 2; BAX, apoptosis regulator BAX; p-AKT, phosphorylated RAC- $\alpha$ serine/threonine-protein kinase; c-Myc, Myc proto-oncogene protein.

overexpression is associated with a poor prognosis in patients with breast cancer (48). However, the underlying mechanism of c-Myc overexpression in basal-like breast tumors remains undefined. Activated AKT may promote tumor cell epithelial-mesenchymal transition by downregulating E-cadherin and $\beta$-catenin expression, and upregulating mesenchymal vimentin expression, leading to enhanced tumor cell mobility (49). Following MMP-1-knockdown with MMP-1 shRNA, the expression of c-Myc, p-AKT and AKT protein was decreased in TNBC cells. Studies have revealed that MMP-1 exhibits a direct signaling 
capability through protease-activated receptor 1 (PAR1) activation, besides the well-known mechanism of MMP-induced extracellular matrix degradation (50), and that MMP-1 suppression reduces intratumoral vascular permeability, tumor cell intravasation and subsequent metastasis through the deactivation of endothelial PAR1 (51). However, further investigation is required with regard to whether MMP-1 promotes breast cancer metastasis through angiogenesis. The present study revealed that MMP-1 had an effect on the activation of AKT/c-Myc signaling, which further supports the results of previous studies. Liu et al (20) observed that MMP-1 exhibited a pro-survival function in tumor cells via PI3K/AKT activation in esophageal squamous cell carcinoma. Another study demonstrated that AKT1 overexpression promoted tumor cell migration (52). Therefore, the MMP-1-regulated PI3K/AKT/c-Myc pathways in TNBC cells merit further investigation.

Lastly, Bcl-2 expression does not differ between TNBC and non-TNBC, but higher Bcl-2 expression has been revealed to be associated with favorable prognostic factors in breast cancer (53). $\mathrm{BAX}$ is a pro-apoptotic $\mathrm{Bcl}-2$ protein family member and serves a role in regulating mitochondria-dependent apoptosis, whereas $\mathrm{Bcl}-2$ is an anti-apoptotic protein that is able to neutralize BAX function in inducing cell death (54-56). The initiation of extrinsic and/or intrinsic apoptotic pathways leads to the activation of various caspases, while BAX expression may induce the sensitivity of tumor cells to apoptotic agents and inhibit the growth of tumor lesions. The present in vitro study demonstrated that Bcl-2 expression was markedly decreased, whereas the expression of BAX and caspase 3 proteins was increased in the shRNA-MMP-1-transfected MCF-7 and MDA-MB-231 cells compared with that of negative control cells.

The results of the present study demonstrate that MMP-1 is differentially regulated in breast cancer tissues and serves a role in breast cancer invasion and metastasis. Therefore, MMP-1 may be of great value and should be further studied as a diagnostic marker and drug target for breast cancer.

\section{Acknowledgements}

The authors would like to thank Dr. Yi-Wei Wang of Shenyang Medical College (Shenyang, China) and Dr. Ping Li of Taian City Central Hospital (Taian, China) for technical assistance in the present study.

\section{Funding}

No funding was received.

\section{Availability of data and materials}

All data generated or analyzed during this study are included in this published article.

\section{Authors' contributions}

QMW and LFW substantially contributed to the conception, design, acquisition of data, analysis and interpretation of data and drafting the article. LL performed experiments and data analysis and revised the manuscript, while YT and LZ assisted in the design of the present study and drafted and revised the manuscript. All authors read and approved the final manuscript.

\section{Ethics and consent to participate}

The research protocol of the present study was approved by the Ethics Committee of The Second Hospital of Dalian Medical University (certification no. 2017-39), and written informed consent was obtained from all patients before enrollment into this study protocol.

\section{Patient consent for publication}

All patients provided consent for the publication of the present manuscript and all their identifiable information were removed during data analyses.

\section{Competing interests}

The authors declare that they have no competing interests.

\section{References}

1. Stewart BW and Wild CP: World cancer report 2014. Int Agency Res Cancer, 2014.

2. Torre LA, Islami F, Siegel RL, Ward EM and Jemal A: Global Cancer in Women: Burden and Trends.Cancer Epidemiol Biomarkers Prev 26: 444-457, 2017.

3. Reeder JG and Vogel VG: Breast cancer prevention. Cancer Treat Res 141: 149-164, 2008.

4. Sotiriou $\mathrm{C}$ and Pusztai L: Gene-expression signatures in breast cancer. N Engl J Med 360: 790-800, 2009.

5. Romond EH, Perez EA, Bryant J, Suman VJ, Geyer CE Jr, Davidson NE, Tan-Chiu E, Martino S, Paik S, Kaufman PA, et al: Trastuzumab plus adjuvant chemotherapy for operable HER2-positive breast cancer. N Engl J Med 353: 1673-1684, 2005.

6. De Giorgi U, Rosti G, Frassineti L, Kopf B, Giovannini N, Zumaglini $\mathrm{F}$ and Marangolo M: High-dose chemotherapy for triple negative breast cancer. Ann Oncol 18: 202-203, 2007.

7. de Ruijter TC, Veeck J, de Hoon JP, van Engeland M and Tjan-Heijnen VC: Characteristics of triple-negative breast cancer. J Cancer Res Clin Oncol 137: 183-192, 2011.

8. Massova I, Kotra LP, Fridman R and Mobashery S: Matrix metalloproteinases: Structures, evolution, and diversification. FASEB J 12: 1075-1095, 1998.

9. Golubkov VS and Strongin AY: Proteolysis-driven oncogenesis. Cell Cycle 6: 147-150, 2007.

10. Sternlicht MD and Werb Z: How matrix metalloproteinases regulate cell behavior. Annu Rev Cell Dev Biol 17: 463-516, 2001.

11. Visse R and Nagase H: Matrix metalloproteinases and tissue inhibitors of metalloproteinases: Structure, function, and biochemistry. Circ Res 92: 827-839, 2003.

12. Brinckerhoff CE, Rutter JL and Benbow U: Interstitial collagenases as markers of tumor progression. Clin Cancer Res 6: 4823-4830, 2000.

13. Roy R, Yang $\mathrm{J}$ and Moses MA: Matrix metalloproteinases as novel biomarkers and potential therapeutic targets in human cancer. J Clin Oncol 27: 5287-5297, 2009.

14. Shin DH, Dier U, Melendez JA and Hempel N: Regulation of MMP-1 expression in response to hypoxia is dependent on the intracellular redox status of metastatic bladder cancer cells. Biochim Biophys Acta 1852: 2593-2602, 2015.

15. Ozden F, Saygin C, Uzunaslan D, Onal B, Durak H and Aki H: Expression of MMP-1, MMP-9 and TIMP-2 in prostate carcinoma and their influence on prognosis and survival. J Cancer Res Clin Oncol 139: 1373-1382, 2013.

16. Cai QW, Li J, Li XQ, Wang JQ and Huang Y: Expression of STAT3, MMP-1 and TIMP-1 in gastric cancer and correlation with pathological features. Mol Med Rep 5: 1438-1442, 2012.

17. Boström P, Söderström M, Vahlberg T, Söderström KO, Roberts PJ, Carpén O and Hirsimäki P: MMP-1 expression has an independent prognostic value in breast cancer. BMC Cancer 11: 348, 2011. 
18. Tavassoli FA and Devilee P: Pathology and genetics of tumours of the breast and female genital organs. Int Agency Res Cancer, 2003.

19. Wolff AC, Hammond ME, Hicks DG, Dowsett M, McShane LM, Allison KH, Allred DC, Bartlett JM, Bilous M, Fitzgibbons P, et al: Recommendations for human epidermal growth factor receptor 2 testing in breast cancer: American Society of Clinical Oncology/College of American Pathologists clinical practice guideline update. J Clin Oncol 31: 3997-4013, 2013.

20. Liu M, Hu Y, Zhang MF, Luo KJ, Xie XY, Wen J, Fu JH and Yang H: MMP1 promotes tumor growth and metastasis in esophageal squamous cell carcinoma. Cancer Lett 377: 97-104, 2016.

21. Ala-aho R and Kähäri VM: Collagenases in cancer. Biochimie 87: 273-286, 2005

22. Schütz A, Röser K, Klitzsch J, Lieder F, Aberger F, Gruber W, Mueller KM, Pupyshev A, Moriggl R and Friedrich K: Lung adenocarcinomas and lung cancer cell lines show association of MMP-1 expression with STAT3 activation. Transl Oncol 8: 97-105, 2015

23. Zhou R, Xu L, Ye M, Liao M, Du H and Chen H: Formononetin inhibits migration and invasion of MDA-MB-231 and 4T1 breast cancer cells by suppressing MMP-2 and MMP-9 through PI3K/AKT signaling pathways. Horm Metab Res 46: 753-760, 2014.

24. Schveigert D, Cicenas S, Bruzas S, Samalavicius NE, Gudleviciene $Z$ and Didziapetriene J: The value of MMP-9 for breast and non-small cell lung cancer patients' survival. Adv Med Sci 58: 73-82, 2013

25. Gialeli C, Theocharis AD and Karamanos NK: Roles of matrix metalloproteinases in cancer progression and their pharmacological targeting. FEBS J 278: 16-27, 2011.

26. Sørlie T, Perou CM, Tibshirani R, Aas T, Geisler S, Johnsen H, Hastie T, Eisen MB, van de Rijn M, Jeffrey SS, et al: Gene expression patterns of breast carcinomas distinguish tumor subclasses with clinical implications. Proc Natl Acad Sci USA 98: 10869-10874, 2001

27. Cleator S, Heller W and Coombes RC: Triple-negative breast cancer: Therapeutic options. Lancet Oncol 8: 235-244, 2007.

28. Prati R, Apple SK, He J, Gornbein JA and Chang HR: Histopathologic characteristics predicting HER-2/neu amplification in breast cancer. Breast J 11: 433-439, 2005.

29. Köhrmann A, Kammerer U, Kapp M, Dietl J and Anacker J: Expression of matrix metalloproteinases (MMPs) in primary human breast cancer and breast cancer cell lines: New findings and review of the literature. BMC Cancer 9: 188, 2009.

30. Yokoyama M, Ochi K, Ichimura M, Mizushima T, Shinji T, Koide N, Tsurumi T, Hasuoka $\mathrm{H}$ and Harada M: Matrix metalloproteinase-2 in pancreatic juice for diagnosis of pancreatic cancer. Pancreas 24: 344-347, 2002.

31. Hilska M, Roberts PJ, Collan YU, Laine VJ, Kössi J, Hirsimäki P, Rahkonen $\mathrm{O}$ and Laato M: Prognostic significance of matrix metalloproteinases-1, $-2,-7$ and -13 and tissue inhibitors of metalloproteinases-1, $-2,-3$ and -4 in colorectal cancer. Int J Cancer 121: 714-723, 2007

32. Lengyel E, Schmalfeldt B, Konik E, Späthe K, Härting K, Fenn A, Berger U, Fridman R, Schmitt M, Prechtel D and Kuhn W: Expression of latent matrix metalloproteinase 9 (MMP-9) predicts survival in advanced ovarian cancer. Gynecol Oncol 82: 291-298, 2001

33. Morgia G, Falsaperla M, Malaponte G, Madonia M, Indelicato M, Travali S and Mazzarino MC: Matrix metalloproteinases as diagnostic (MMP-13) and prognostic (MMP-2, MMP-9) markers of prostate cancer. Urol Res 33: 44-50, 2005.

34. Mannello F: What does matrix metalloproteinase-1 expression in patients with breast cancer really tell us? BMC Med 9: 95, 2011.

35. Xuan J, Zhang Y, Zhang X and Hu F: Matrix metalloproteinase-1 expression in breast cancer and cancer-adjacent tissues by immunohistochemical staining. Biomed Rep 3: 395-397, 2015.

36. Cierna Z, Mego M, Janega P, Karaba M, Minarik G, Benca J, Sedlácková T, Cingelova S, Gronesova P, Manasova D, et al: Matrix metalloproteinase 1 and circulating tumor cells in early breast cancer. BMC Cancer 14: 472, 2014.

37. Przybylowska K, Kluczna A, Zadrozny M, Krawczyk T, Kulig A, Rykala J, Kolacinska A, Morawiec Z, Drzewoski J and Blasiak J: Polymorphisms of the promoter regions of matrix metalloproteinases genes MMP-1 and MMP-9 in breast cancer. Breast Cancer Res Treat 95: 65-72, 2006
38. Kousidou OC, Roussidis AE, Theocharis AD and Karamanos NK Expression of MMPs and TIMPs genes in human breast cancer epithelial cells depends on cell culture conditions and is associated with their invasive potential. Anticancer Res 24 4025-4030, 2004.

39. Roy R, Louis G, Loughlin KR, Wiederschain D, Kilroy SM, Lamb CC, Zurakowski D and Moses MA: Tumor-specific urinary matrix metalloproteinase fingerprinting: Identification of high molecular weight urinary matrix metalloproteinase species. Clin Cancer Res 14: 6610-6617, 2008.

40. Koç M, Ediger D, Budak F, Karadağ M, Oral HB, Uzaslan E, Ege E and Gözü RO: Matrix metalloproteinase-9 (MMP-9) elevated in serum but not in bronchial lavage fluid in patients with lung cancer. Tumori 92: 149-154, 2006.

41. Liu H, Kato Y, Erzinger SA, Kiriakova GM, Qian Y, Palmieri D, Steeg PS and Price JE: The role of MMP-1 in breast cancer growth and metastasis to the brain in a xenograft model. BMC Cancer 12: 583, 2012.

42. Hu F, Wang C, Guo S, Sun W, Mi D, Gao Y, Zhang J, Zhu T and Yang S: $\delta E F 1$ promotes osteolytic metastasis of MDA-MB-231 breast cancer cells by regulating MMP-1 expression. Biochim Biophys Acta 1809: 200-210, 2011.

43. Wyatt CA, Geoghegan JC and Brinckerhoff CE: Short hairpin RNA-mediated inhibition of matrix metalloproteinase-1 in MDA-231 cells: Effects on matrix destruction and tumor growth. Cancer Res 65: 11101-11108, 2005.

44. Dang CV: MYC on the path to cancer. Cell 149: 22-35, 2012.

45. Ben-Porath I, Thomson MW, Carey VJ, Ge R, Bell GW, Regev A and Weinberg RA: An embryonic stem cell-like gene expression signature in poorly differentiated aggressive human tumors. Nat Genet 40: 499-507, 2008.

46. Chandriani S, Frengen E, Cowling VH, Pendergrass SA, Perou CM, Whitfield ML and Cole MD: A core MYC gene expression signature is prominent in basal-like breast cancer but only partially overlaps the core serum response. PLoS One 4: e6693, 2009.

47. Xu J, Chen Y and Olopade OI: MYC and breast cancer. Genes Cancer 1: 629-640, 2010.

48. Wolfer A, Wittner BS, Irimia D, Flavin RJ, Lupien M, Gunawardane RN, Meyer CA, Lightcap ES, Tamayo P, Mesirov JP, et al: MYC regulation of a 'poor-prognosis' metastatic cancer cell state. Proc Natl Acad Sci USA 107: 3698-3703, 2010.

49. Smith PG, Wang F, Wilkinson KN, Savage KJ, Klein U, Neuberg DS, Bollag G, Shipp MA and Aguiar RC: The phosphodiesterase PDE4B limits cAMP-associated PI3K/AKT-dependent apoptosis in diffuse large B-cell lymphoma. Blood 105: 308-316, 2005.

50. Boire A, Covic L, Agarwal A, Jacques S, Sherifi S and Kuliopulos A: PAR1 is a matrix metalloprotease-1 receptor that promotes invasion and tumorigenesis of breast cancer cells. Cell 120: 303-313, 2005 .

51. Juncker-Jensen A, Deryugina EI, Rimann I, Zajac E, Kupriyanova TA, Engelholm LH and Quigley JP: Tumor MMP-1 activates endothelial PAR1 to facilitate vascular intravasation and metastatic dissemination. Cancer Res 73: 4196-4211, 2013.

52. Gupta AK, Cerniglia GJ, Mick R, Ahmed MS, Bakanauskas VJ, Muschel RJ and McKenna WG: Radiation sensitization of human cancer cells in vivo by inhibiting the activity of PI3K using LY294002. Int J Radiat Oncol Biol Phys 56: 846-853, 2003.

53. Kallel-Bayoudh I, Hassen HB, Khabir A, Boujelbene N, Daoud J, Frikha M, Sallemi-Boudawara T, Aifa S and Rebaï A: Bcl-2 expression and triple negative profile in breast carcinoma. Med Oncol 28 (Suppl 1): S55-S61, 2011.

54. Sun B and Xu M: Matrine inhibits the migratory and invasive properties of nasopharyngeal carcinoma cells. Mol Med Rep 11: 4158-4164, 2015.

55. Czabotar PE, Lessene G, Strasser A and Adams JM: Control of apoptosis by the BCL-2 protein family: Implications for physiology and therapy. Nat Rev Mol Cell Biol 15: 49-63, 2014.

56. Lin W and Tongyi S: Role of Bax/Bcl-2 family members in green tea polyphenol induced necroptosis of p53-deficient Hep3B cells. Tumour Biol 35: 8065-8075, 2014.

This work is licensed under a Creative Commons Attribution-NonCommercial-NoDerivatives 4.0 International (CC BY-NC-ND 4.0) License. 